\title{
Treatment of Intradural Spinal Arteriovenous Fistula: Technical Case Report
}

\section{Tratamento de fístula arteriovenosa espinhal intradural: relato de caso técnico}

\author{
Helbert de Oliveira Manduca Palmiero ${ }^{1}$ Ricardo Lourenço Caramanti ${ }^{1}$ \\ Feres Eduardo Aparecido Chaddad-Neto ${ }^{1}$ \\ ${ }^{1}$ Universidade Federal de São Paulo (Unifesp), São Paulo, \\ São Paulo, Brazil \\ Address for correspondence Helbert de Oliveira Manduca Palmiero, \\ MD, Unifesp, São Paulo, SP 04021-001, Brazil \\ (e-mail: helbertpalmiero@yahoo.com.br).
}

Arq Bras Neurocir 2017;36:264-268.

Abstract

Keywords
- intradural spinal
arteriovenous fistula
- embolization
- microsurgical
technique
Resumo

received

August 18, 2017

accepted

October 17, 2017

published online

December 7, 2017
Introduction Although rare, arteriovenous fistula (AVF) is the most common vascular malformation of the spine, and it is mainly located in the thoracic region. The fistula is identified by arteriography, which enables the treatment by embolization or guides the microsurgical therapy.

Clinical Presentation We describe the case of a 61-year-old woman with neurogenic claudication evolving to paraparesis. A dorsal intradural AVF was identified by magnetic resonance imaging (MRI) and arteriography, and it was submitted to an embolization, but the procedure was unsuccessful. The patient was then referred for neurosurgery, and the AVF was obliterated using a microsurgical technique guided by multimodal intraoperative monitoring. We identified the AVF in the intraoperative moment and we then cut and coagulated the extradural portion of the nerve root.

Discussion Arteriovenous fistulas occur in the dura mater of the nerve roots with the arterialization of the venous plexus. The treatment prevents the progression of the deficits. While performing diagnostic arteriography, attempts of embolization are possible.

Conclusion Although the initial attempt of embolization at the moment of the diagnostic arteriography is achievable, it has failure rates of $50 \%$, unlike the surgical treatment, which is definitive in all cases, as reported in this article.

Introdução Apesar de raras, as fístulas arteriovenosas (FAV) são as malformações vasculares mais comuns na coluna, localizadas essencialmente na região torácica. A fístula é identificada por arteriografia, a qual permite o tratamento da embolização ou guia a terapia microcirúrgica.

Apresentação Clínica Descrevemos o caso de uma mulher de 61 anos com claudicação neurogênica evoluindo para paraparesia. Uma FAV intradural dorsal foi identificada por meio de ressonância magnética (RM) e arteriografia, e foi submetida a uma embolização, mas o procedimento não obteve sucesso. A paciente foi então 
encaminhada para tratamento neurocirúrgico, e a FAV foi eliminada por técnica microcirúrgica guiada por monitoração multimodal intraoperatória. Identificamos a FAV durante o período intraoperatório, e em seguida cortamos e coagulamos a porção

Palavras-chave

- fístula

arteriovenosa espinhal intradural

- embolização

- técnica microcirúrgica extradural da raiz do nervo.

Discussão As AVFs ocorrem na dura-máter das raízes neurais com a arterialização do plexo venoso. O tratamento evita o progresso de déficits. Durante a arteriografia diagnóstica, tentativas de embolização são possíveis.

Conclusão Apesar de a tentativa inicial de embolização durante a arteriografia ser possível, ela tem probabilidades de $50 \%$ de sucesso, enquanto o tratamento cirúrgico é definitivo em todos os casos, como relatado neste artigo.

\section{Background and Importance}

Although rare, arteriovenous fistulas (AVFs) are the most common spinal vascular malformations, and are mainly located in the thoracic region. Neurogenic claudication is the most common clinical presentation, and it is often mistaken for lumbar stenosis. Magnetic resonance imaging (MRI) complements the diagnosis, but the gold-standard procedure is arteriography. Through arteriography, one can identify the AVF and treat it with embolization, or the procedure can guide the microsurgical treatment. While in the literature we can find information corroborating the endovascular first approach, ${ }^{1}$ in the present article we demonstrate the efficacy of the microsurgical treatment.

\section{Clinical Presentation}

A 61-year-old woman presented at the outpatient clinic complaining of low back pain and gait disturbance. The clinical presentation had been progressing for $\sim 6$ months with paresis and sensory loss in the limbs, in addition to urinary dysfunction. She did not have diabetes, arterial nor trauma due to tumble.

A physical examination revealed slow gait, grade 4 paraparesis, exalted patellar and Achilles reflexes, and normal plantar cutaneous reflexes. Tactile hypoesthesia with a sensitive level in L2 was associated. The first treatment was conservative; we considered the hypothesis of lumbar stenosis until the complementary exams.

The MRI (-Fig. 1) demonstrated a normal spinal canal, but with a medullary hypersignal in the lumbar up to the cone regions associated with serpiginous vessels near the dorsal medullary region as flow-voids. Later, the hypothesis of dorsal intradural AVF was confirmed by arteriography.

The fistula embolization was attempted during the arteriography, but without success (see preoperative arteriography with elements of embolization near the fistula region, - Fig. 2). The patient presented aggravation in her limb movements and grade 2 paraparesis. She was referred to neurosurgery, and the microsurgical treatment was performed.

The team determined the fistula's topography with intraoperative fluoroscopy during the surgery. We used information from the interventionist team on the site of the fistula: to the left, at the level of T11. Then, we proceeded to the laminotomy from T10 to T12. The dural opening was made with a number 15 blade and Metzembaum scissors. We spotted the engorged veins under the subarachnoid space.

By means of microsurgical technique, the fistulous path was identified at the level of the 10th left thoracic root (-Fig. 3). Sensitive and motor roots were also identified at the drainage vein in the neural root entry, and preserved during surgery (-Fig. 4). The drainage vein was compressed with a bipolar forceps under electrophysiological monitoring, and, as we did not observe any decrease in motor potentials, we proceeded to the final bipolar coagulation, and cut with microsurgery scissors (- Fig. 5A, B and C).

As we performed the dural eversion, enlarged vessels were observed in the extradural face of the neural root. Therefore, these vessels were also submitted to cauterization (-Fig. 5D). We closed the dura mater using 4-0 polydioxanone sutures (PDS), and the laminotomy using mini-plates.

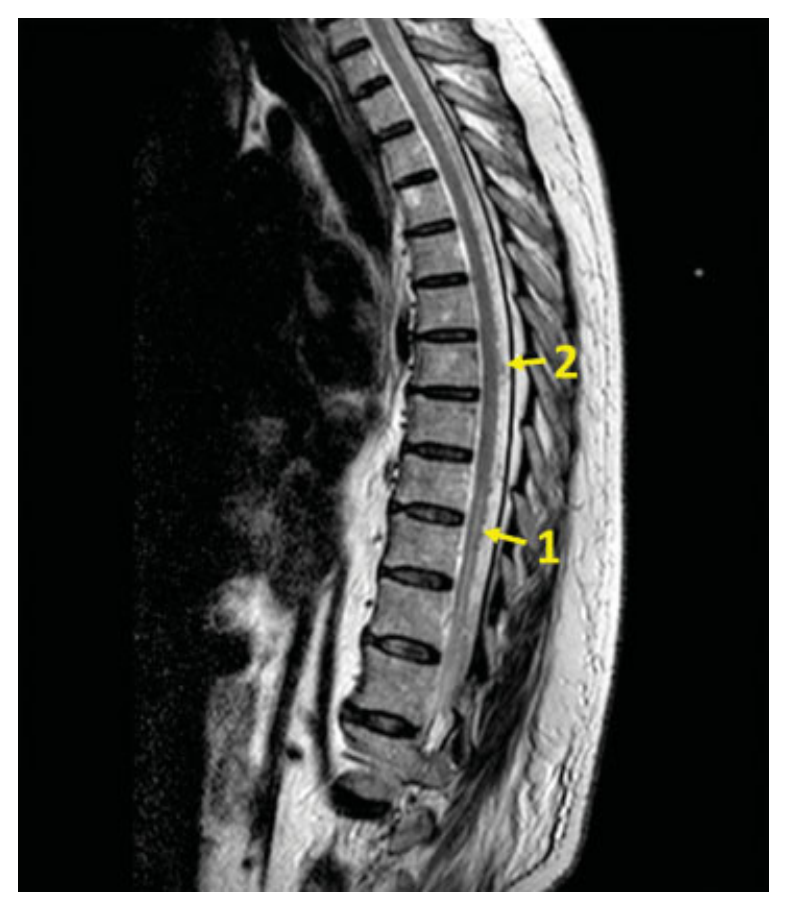

Fig. 1 Magnetic resonance imaging with medullary hypersignal in the cone region (1), and serpiginous vessels near the dorsal medullary region as flow-voids (2). 


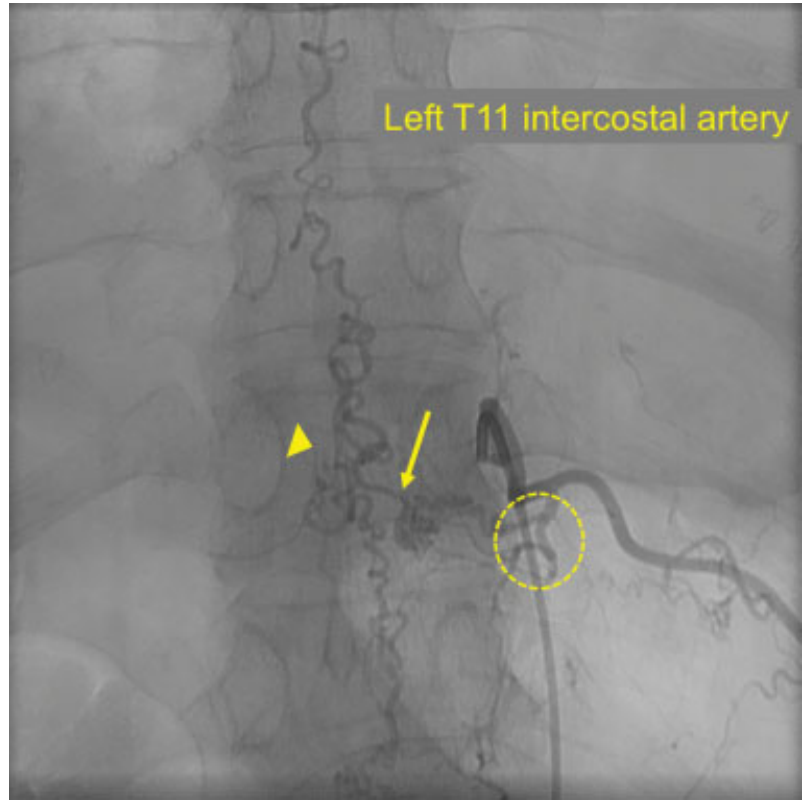

Fig. 2 Arteriography in which the left T11 intercostal thoracic artery was catheterized, above the Adamkiewicz artery, and identification of the fistula (arrow), the venous ectasia (arrow head), and the elements of the previous embolization (circle).

\section{Discussion}

There are many types of spinal vascular malformations. ${ }^{2}$ However, the classification made by Spetzler et al, which was based on a case series, ${ }^{5}$ is the most used. It has been divided into two main groups: AVFs and arteriovenous malformations. ${ }^{3}$ The AVF with intradural drainage is the most common, and it usually occurs in the thoracic region, ${ }^{4}$ as we exemplified in the present clinical case.

The artery of Adamkiewicz is the main medullary nutrition source in the thoracolumbar region; it is located between T9$\mathrm{T} 12$ in the left side. Identifying this artery is important because it enables the embolization of root branches in this spinal topography, if the artery of Adamkiewicz is not involved. ${ }^{3}$
Spinal AVFs occur in the dura-mater of the roots, leading to arterialization of the venous plexus, venous hypertension and medullary ischemic myelopathy., 3

With probable acquired cause, AVFs have progressive clinical manifestation and initially present sensitive deficits (in $80 \%$ of the cases), paresis (70\%) and sphincter dysfunction (62.5\%). ${ }^{1}$ Neurogenic claudication is often mistaken for lumbar stenosis, which leads to a delay in the diagnosis. ${ }^{1}$ With time, motor deficits and gait disturbances progress. ${ }^{3}$

The diagnosis is suggested in the MRI exam when there is medullary hypersignal, as well as serpiginous perimedullary vessels seen as flow-voids in the dorsal surface. ${ }^{3}$

The arteriography is the gold-standard examination, and specific protocols determine the artery of Adamkiewicz level and venous stasis, suggesting the AVF site. During the arteriography, the level of AVF is identified by the vertebral body and side. $^{5}$

Arteriovenous fistulas should be treated as soon as diagnosed to prevent the progression to severe and irreversible deficits that occur if the time between diagnosis and therapy reaches 3 years. ${ }^{5,6}$ Thus, the goal of the treatment is to stop the progression of the myelopathy, or even to reverse the deficits by restoring spinal perfusion. ${ }^{3}$

Studies demonstrate that there are no differences in the obliteration rates between the endovascular and microsurgical treatments, enabling the migration from embolization to surgery, either due to the impossibility of embolization, or due to inadequate occlusion. ${ }^{7}$

Some services suggest that the initial attempt of embolization at the moment of the diagnostic arteriography is feasible; however, it has failure rates of $50 \%, 4,7$ unlike the surgical treatment, which is definitive in all cases. ${ }^{4}$

For proper embolization, it should be possible to navigate with the microcatheter to the fistulous point where the liquid emboligenic agent is injected, ${ }^{3}$ which is not always possible, as in the present case.

During surgery, the site of the fistulous point should be identified at the exit of the nerve root, enabling the clipping, or clotting and cutting of the fistulous connection. ${ }^{3}$ Multimodal

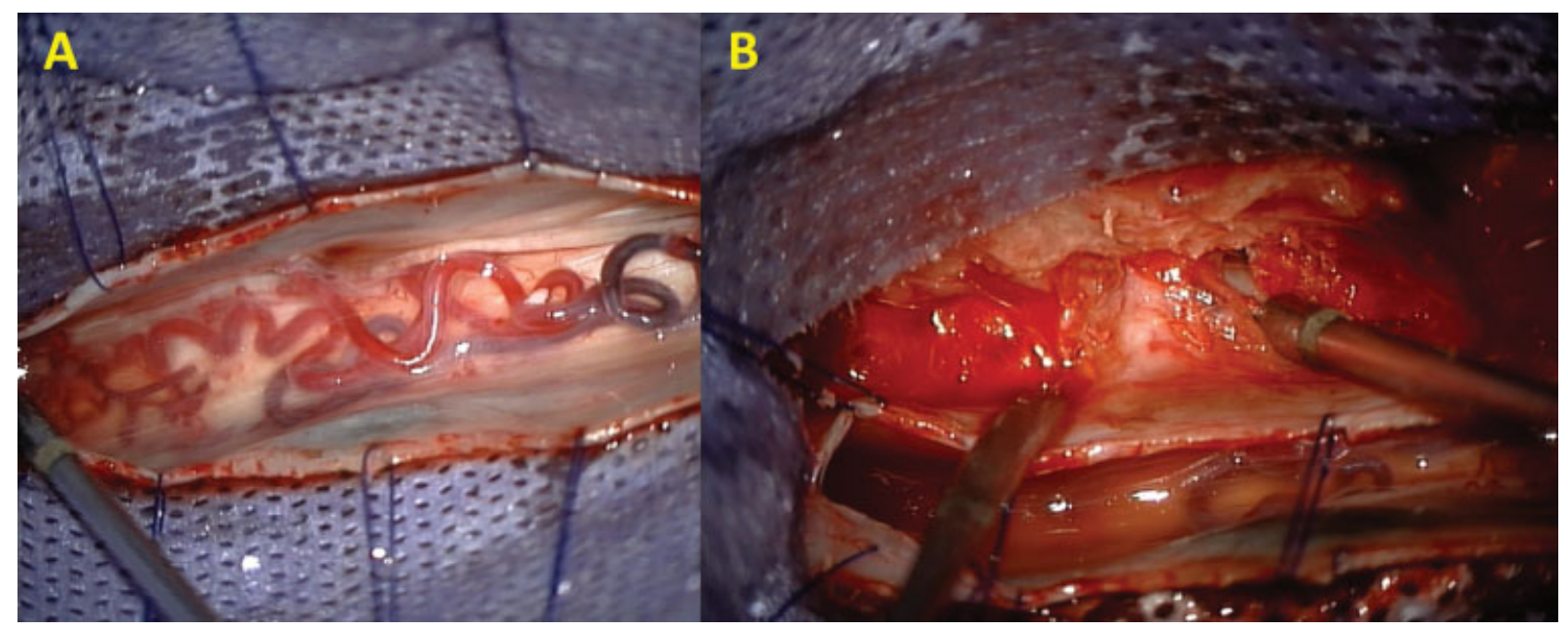

Fig. 3 (A) Identification of the intradural fistula, as well as the venous ectasia, over the medullary region. (B) Identification of the extradural face of the neural root at the level of the fistula. 


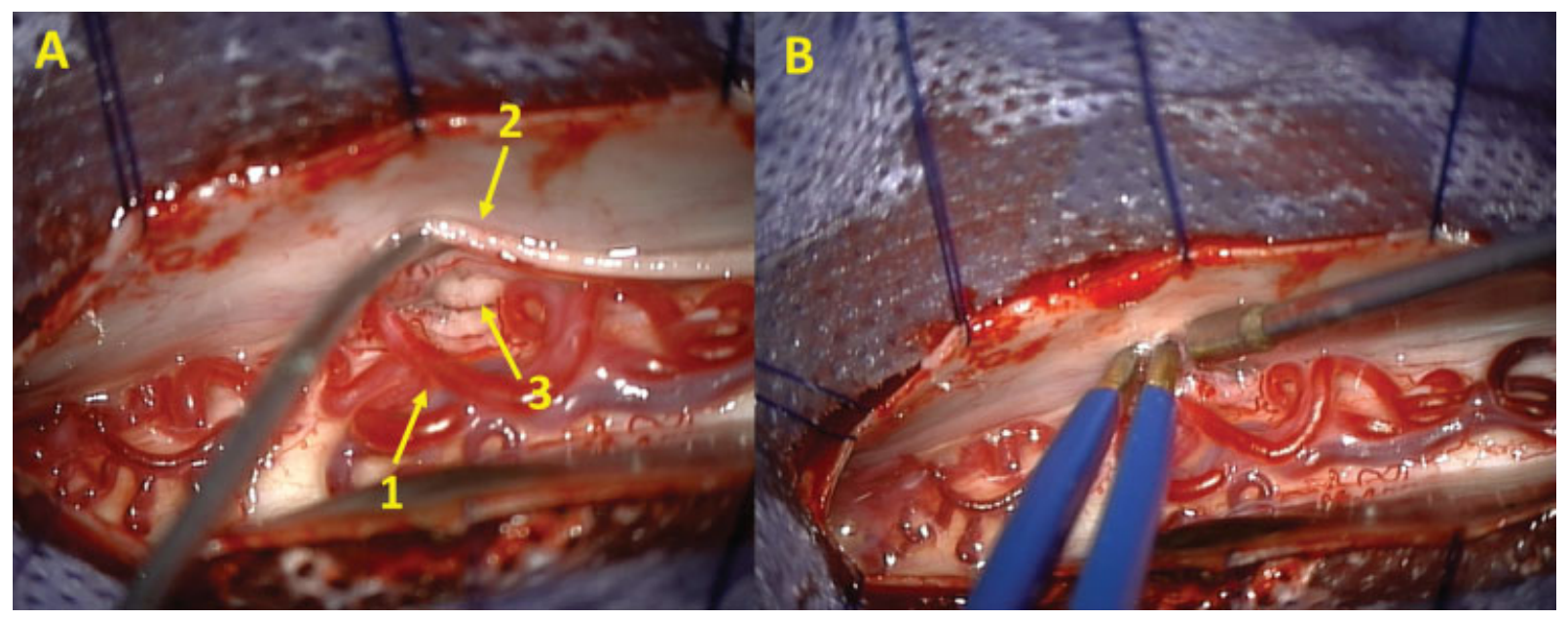

Fig. 4 (A) Identification of the venous ectasia together with the fistula (1); the dorsal sensitive root, (2); and the ventral motor root, (3) (B) Compression of the fistula with a bipolar forceps while the neurologist performs the electromonitoring.

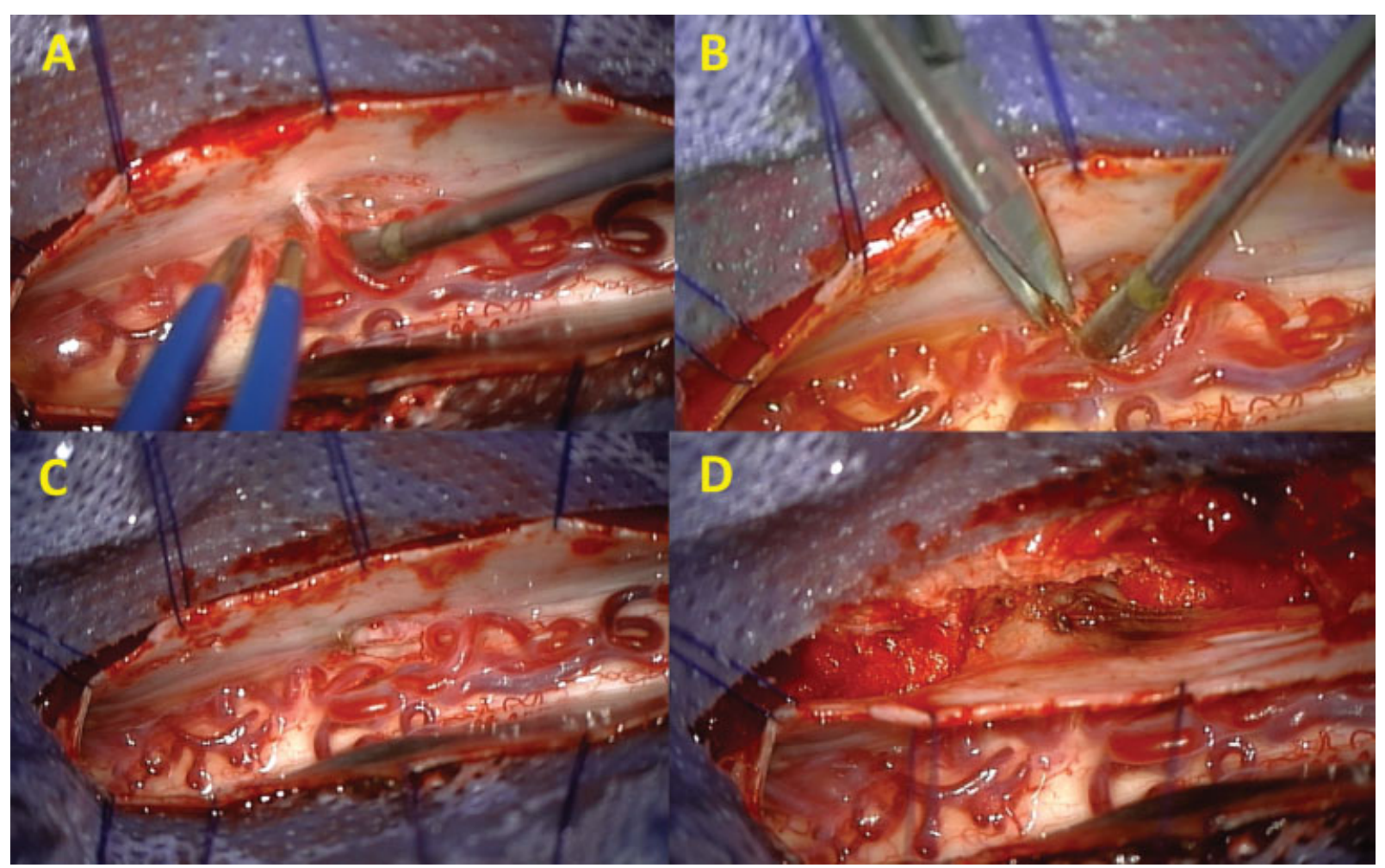

Fig. 5 (A) Coagulation of the fistula with a bipolar forceps; (B) Cutting of the fistula with microsurgical scissors; (C) The ecstasiated veins were identified after the obliteration of the fistula; (D) The treatment was complemented performing the extradural root coagulation with a bipolar forceps.

intraoperative monitoring increases the safety of the procedure, ${ }^{3}$ so we performed it with the patient described. Venus compression with bipolar forceps is one possibility, clipping the vein under electromonitoring before definitive occlusion is the other.

The extradural inspection of the nerve root after cutting the fistulous point reveals the vascularized pedicle; however, arterial nutrition is not always visible, since the fistula occurs between the dural layers. ${ }^{5}$ Thus, part of the surgical tech- nique involves extradural coagulation at the height of the involved nerve root.

Measures of epidural venous pressure reveal a drop from $40 \mathrm{mmHg}$ before the treatment to $23 \mathrm{mmHg}$ after obliteration of the fistula with subsequent reduction of the venous flow. ${ }^{5}$

The patient was submitted to a successful surgical treatment, with the AVF being identified intraoperatively; then, the AVF was submitted to coagulation and cutting, which were complemented with extradural coagulation in the nerve root. 
268 Treatment of Intradural Spinal AVF: Technical Case Report Palmiero et al.

The deficits were maintained in the immediate postoperative period, and after the discharge from the hospital, no new complications were identified.

\section{Conclusion}

Arteriovenous fistulas have progressive clinical manifestation, and should be treated as soon as diagnosed to prevent the progression to severe and irreversible deficits. Thus, the goal of the treatment is to stop the progression of the myelopathy. The initial attempt of embolization at the moment of diagnostic arteriography is possible, but it has failure rates of $50 \%$, unlike the surgical treatment, which is definitive in all cases. The patient was submitted to a successful surgical treatment, and physical therapy rehabilitation was indicated.

Conflicts of Interest

The authors have no conflicts of interest to disclose.

\section{References}

1 Lee J, Lim YM, Suh DC, Rhim SC, Kim SJ, Kim KK. Clinical presentation, imaging findings, and prognosis of spinal dural arteriovenous fistula. J Clin Neurosci 2016;26:105-109

2 Takai K. Spinal arteriovenous shunts: angioarchitecture and historical changes in classification. Neurol Med Chir (Tokyo) 2017;57(07): 356-365. Doi: 10.2176/nmc.ra.2016-0316

3 Flores BC, Klinger DR, White JA, Batjer HH. Spinal vascular malformations: treatment strategies and outcome. Neurosurg Rev 2017; 40(01):15-28

4 Koch MJ, Stapleton CJ, Agarwalla PK, et al. Open and endovascular treatment of spinal dural arteriovenous fistulas: a 10-year experience. J Neurosurg Spine 2017;26(04):519-523

5 Spetzler RF, Detwiler PW, Riina HA, Porter RW. Modified classification of spinal cord vascular lesions. J Neurosurg 2002;96(2,Suppl)145-156

6 Sanborn MR, Crowley RW, Uschold T, Park MS, Albuquerque FC, McDougall CG. Spinal dural arteriovenous fistulas: how, when, and why. Neurosurgery 2014;61(01, Suppl 1):6-11

7 Gross BA, Albuquerque FC, Moon K, McDougall CG. Validation of an 'endovascular-first' approach to spinal dural arteriovenous fistulas: an intention-to-treat analysis. J Neurointerv Surg 2017;9(01):102-105 